\title{
Feasibility study to evaluate compliance of physical activity over a long time period and its influence on the total activity score, glucose metabolism and physical and psychological parameters following breast cancer
}

\author{
THORSTEN SCHMIDT ${ }^{1}$, MADALENA SCHWARZ ${ }^{2}$, MARION VAN MACKELENBERGH ${ }^{2}$, WALTER JONAT ${ }^{2}$, \\ BURKHARD WEISSER ${ }^{3}$, CHRISTOPH RÖCKEN $^{1}$ and CHRISTOPH MUNDHENKE ${ }^{2}$ \\ ${ }^{1}$ Comprehensive Cancer Center North; ${ }^{2} \mathrm{OB} / \mathrm{GYN}$, Breast Unit, University of Kiel, UKSH, \\ D-24105 Kiel; ${ }^{3}$ Institute of Sport Science, University of Kiel, D-2408 Kiel, Germany
}

Received February 3, 2016; Accepted October 19, 2016

DOI: $10.3892 /$ mco.2017.1144

\begin{abstract}
Despite recommendations that patients with breast cancer ought to undertake physical exercise, a majority of breast cancer patients fail to change their lifestyle and to increase their physical activity following diagnosis. In this clinical intervention feasibility study, compliance and sustainability of a walking training program over 24 weeks in patients with breast cancer following treatment were examined. The endpoints were retention rates after 12 and 24 weeks (6 months) and serum levels of glucose metabolism, the total activity score, endurance, a subjectively perceived exertion-during-endurance stress test, quality of life and fatigue. A supervised walking training session for 60-75 min twice-weekly over 6 months in 35 patients with breast cancer following treatment was examined. The study retention at 12 weeks was 27/35 (77\%), and at 24 weeks 24/35 (69\%). After 24 weeks, the glycated hemoglobin (HbA1c) score was significantly lowered following the intervention $(\mathrm{P}=0.001)$. Insulin and glucose levels remained unchanged. Significant improvements were measured in the patients' body mass index $(P=0.001)$, endurance $(P=0.013)$ and in psychological parameters such as fatigue $(\mathrm{P}=0.008)$ and the quality of life $(\mathrm{P}=0.007)$. Furthermore, the patients exhibited significant improvements in their subjectively perceived exertion during an endurance-stress test $(\mathrm{P}=0.079)$ and in their total activity score $(\mathrm{P}=0.931)$. The present study demonstrated an increase
\end{abstract}

Correspondence to: Dr Thorsten Schmidt, Comprehensive Cancer Center North, University of Kiel, UKSH, Arnold-Heller-Street 3, D-24105 Kiel, Germany

E-mail: thorsten.schmidt@uksh.de

Abbreviation: MET, metabolic equivalent of task

Key words: breast cancer, sustainability of physical activity, glucose metabolism in total activity resulting from the supervised walking training program twice-weekly over 6 months. Significant changes in long-term parameters of glucose metabolism, such as in the HbA1c score, also occurred. Furthermore, significant improvements in physical and psychological parameters were observed.

\section{Introduction}

Breast cancer is currently the most common malignancy among women. Breast cancer patients frequently report a decline in physical fitness and quality of life, as well as an increase in fatigue. Obesity or overweight in patients is not only associated with higher rates of morbidity and mortality (1), but also with fatigue and arthralgia (2-5).

In recent years, physical activity has become an important topic in cancer therapy, serving a vital role in cancer prevention and control. Physical activity has been proposed as an adequate intervention for women with breast cancer in order to improve their quality of life and physical strength. There are specific recommendations for physical exercise in patients with breast cancer in aftercare. Patients are recommended to be physically active for a period of 3-5 h per week [10 metabolic equivalents of task (MET)/h per week, with $4 \mathrm{MET} / \mathrm{h}$ per session] (6). Nevertheless, often physical activity is decreased in aftercare $(7,8)$. Irwin et al (9) reported that breast cancer survivors spend more time in a sedentary state compared with controls, and are often overweight or obese (9). Several studies have confirmed that physical activity has a positive influence on preventing recurrence and mortality $(10,11)$. In a systematic review and meta-analysis of epidemiological studies by Lahart et al (12), a significant risk reduction for cancer recurrence by post-diagnostic physical activity has been described [hazard ratio $(\mathrm{HR})=0.52,95 \%$ confidence interval (CI) 0.43-0.64, $\mathrm{P}<0.01$; and $\mathrm{HR}=0.59$, 95\% CI 0.45-0.78, $\mathrm{P}<0.05$, respectively] (12).

A burgeoning body of evidence has demonstrated that there is an association between obesity and a sedentary lifestyle, metabolic syndrome and breast cancer or breast 
cancer recurrence (13-15). Metabolic syndrome includes hypertension, abdominal adiposity, dyslipidemia and glucose dysregulation. There is evidence to suggest that metabolic syndrome determinants may be improved by physical activity in the general population. Few published studies have been reported in the literature on any association among metabolic syndrome, breast cancer and insulin resistance, although previous studies have shown that physical activity may influence or reduce fasting insulin levels and insulin resistance (16-20). High-fasting insulin levels have been associated with distant recurrence and mortality in breast cancer survivors. The situation may be improved by the patient undertaking physical activity over a long time period $(3,19,20)$. To date, only a few studies have examined the effect of physical activity on changes in the levels of insulin, glucose and HbA1c in breast cancer survivors $(13,14,16,21-25)$, and therefore further studies are required in order to determine the effects of physical interventions on metabolic syndrome variables in patients with breast cancer.

The aim of this clinical intervention feasibility study was to verify the compliance and sustainability of a supervised walking training program over a long time period. Additional study endpoints were to assess safety, efficacy, the influence on glucose metabolism, physical and psychological parameters and activity scores.

\section{Materials and methods}

This one-arm feasibility intervention trial examined the compliance of a supervised walking training program in patients with breast cancer following treatment. A total of 35 patients with primary breast cancer were involved in twice-weekly training for 24 weeks. Additional endpoints were the effects of the endurance training on glucose metabolism [glycated hemoglobin (HbA1c), insulin and glucose levels], physical fitness (W/kg per body weight in $\mathrm{kg}$ ), subjectively perceived exertion during an endurance-stress test (on the Borg scale), the total activity score [based on the International Physical Activity Questionnaire (IPAQ)], quality of life (based on the EORTC QLQ C30+BR23 questionnaire) and fatigue [Multidimensional Fatigue Inventory with 20 questions (MFI 20)], at 12 weeks and 6 months after the initiation of physical intervention. The patients were recruited between March and June 2013 in the University of Kiel, UKSH, one of Germany's major academic breast units. The women who were involved had to meet the following eligibility criteria: They had primary breast cancer; they were no more than three years post-operative, they had no metastases; they were aged 18-75 years old; and their physicians had given them clearance to exercise. Exclusion criteria included the existence of acute infectious disease or severe cardiac disease (New York Heart Association functional class $\geq$ III; myocardial infarction $<3$ months), a severe pulmonary or renal insufficiency (glomerular filtration rate $<30 \%$ ), serious neurological disorders, $<10,000$ platelets per $\mathrm{ml}$, hemoglobin $<8 \mathrm{~g} / \mathrm{dl}$ and planned chemo- or radiotherapy within the next 6 months. The present study was approved by the local ethical review committee (registration no.: AZ D 436/13). All participants provided their written informed consent prior to participation in the study.
Per protocol data were assessed at the baseline (T1), after 12 weeks (T2) and after 6 months (T3).

Obtained results at the baseline, T1, were compared with values 12 weeks and 6 months following initiation of training using one-way ANOVA analysis of variance (for the physical fitness and glucose metabolism analyses), the Wilcoxon-test (for the subjectively perceived exertion during endurance-stress test, fatigue and quality of life), and the Friedman test (for the glucose and insulin level measurements). $\mathrm{P}<0.05$ was taken to indicate a statistically significant difference, and the effects were expressed as the mean \pm standard deviation. The analysis was performed using the SPSS system for Windows (version PASW 21; IBM SPSS, Armonk, NY, USA).

For this study, 80 patients were identified retrospectively and contacted between March and August 2013. A total of 35 patients fulfilled the inclusion criteria and were finally enrolled; 45 of the identified patients were unable to participate. Of these, 38 were denied involvement due to the excessive distance from the study center, two had already died, and five were not interested. At the baseline, 35 patients were recruited. Due to timing issues or family problems or withdrawal of consent, eight out of 35 enrolled patients dropped out between $\mathrm{T} 1$ and T2, and an additional three dropped out between T2 and T3. Ultimately, 24 patients completed the study successfully. The patient characteristics (including age and BMI) at baseline T1, T2 and T3 are shown in Table I.

The endurance (W/kg per kg body weight) and subjectively perceived exertion during endurance-stress test (according to the Borg scale) were assessed with the ramp test, 'Physical Worker Capacity Test 150' (PWC 150) as a bicycle ergometer test. For the ramp test, the patient was instructed to cycle at a speed of 60-70 revolutions/min (RPM). The test was started at $25 \mathrm{~W}$, after which the load was increased by $25 \mathrm{~W}$ every $2 \mathrm{~min}$. At the end of each exercise level, the heart rate, blood pressure and well-being based on a numerical scale according to the Borg scale were recorded $(25,26)$. The test was terminated if the patient had a heart rate of 150 beats/min, or the cycling speed fell below 60 RPM. The maximum workload was recorded.

Physical activity was calculated to determine the number of minutes per week of vigorous physical activity, moderate physical activity, walking and total physical activity during leisure time, transport, work and domestic purposes during the past week with the long version of the IPAQ. The IPAQ scores were expressed according to the formula: MET/min per week = average MET level $\mathrm{x}$ min of physical activity $\mathrm{x}$ number of physical activity sessions per week. The overall result of the physical activity analysis was assigned to one of three groups: Low, moderate or high level of physical activity (27).

The European Organization for Research and Treatment of Cancer (EORTC) has developed several validated questionnaires to assess the quality of life of cancer patients in a multidimensional approach. The questionnaire used in the present study was EORTC QLQ C30, version 3 BR23, which was specifically developed for patients with breast cancer. It provided the documentation source of psychological changes. The results section of the questionnaire focuses on quality of life and fatigue $(28,29)$. The fatigue symptoms were assessed using MFI-20. The MFI-20 is a prospectively validated and internationally frequently used questionnaire $(30,31)$. 
Table I. Patient characteristics at T1, T2 and T3.

\begin{tabular}{|c|c|c|c|c|}
\hline Parameter & $\mathrm{T} 1^{\mathrm{a}}$ & $\mathrm{T} 2^{\mathrm{a}}$ & $\mathrm{T}^{\mathrm{a}}$ & P-value \\
\hline No. of patients & 35 & 27 & 24 & \\
\hline Age & $57 \pm 11.92$ & $56 \pm 10.33$ & $58 \pm 9.67$ & 0.806 \\
\hline BMI (kg/m²) & $25.87 \pm 3.5$ & $25.61 \pm 3.38$ & $25.69 \pm 3.47$ & 0.001 \\
\hline \multicolumn{5}{|l|}{ Exercise capacity } \\
\hline (PWC 150) & $1.54 \pm 0.41$ & $1.66 \pm 0.47$ & $1.61 \pm 0.48$ & 0.013 \\
\hline BORG & $15.6 \pm 2.19$ & $15.28 \pm 1.64$ & $14.67 \pm 1.83$ & 0.079 \\
\hline Fatigue (MFI 20) & $11.48 \pm 2.12$ & $10.64 \pm 1.66$ & $10.75 \pm 2.40$ & 0.008 \\
\hline Quality of life & $66.33 \pm 17.43$ & $74.00 \pm 15.46$ & $76.04 \pm 16.17$ & 0.007 \\
\hline HbA1c $(\%)$ & $5.61 \pm 0.56$ & $5.50 \pm 0.59$ & $5.42 \pm 0.54$ & 0.001 \\
\hline Glucose (mg/dl) & $94.76 \pm 27.93$ & $101.42 \pm 23.15$ & $101.91 \pm 23.16$ & 0.40 \\
\hline Insulin (micro-units/ml) & $25.44 \pm 32.88$ & $24.50 \pm 21.39$ & $28.11 \pm 24.99$ & 0.054 \\
\hline
\end{tabular}

${ }^{a}$ T1, baseline; T2, after 12 weeks; T3, after 6 months. Changes in BMI, exercise capacity (PWC 150; measured in W/kg per kg body weight), fatigue (MFI 20), quality of life (EORTC QLQ C30), concentration of HbA1c, glucose and insulin (according to the ANOVA, Friedman and Wilcoxon tests, as detailed in the text). All data are expressed as means \pm standard deviation. ANOVA, analysis of variance; BMI, body mass index; PWC 150, Physical Worker Capacity Test 150; BORG (scale), the subjectively perceived exertion during an endurance-stress test; MFI 20, Multidimensional Fatigue Inventory; HbA1c, glycated hemoglobin.

Endurance training was performed as a supervised walking training program: 60-75 min twice-weekly for 24 weeks. The endurance stress was controlled on the basis of individual treatments, therapy side-effects and the resulting, different psycho-physical capacities of the patients according to the Borg scale. Patients were encouraged to be active at a Borg level of 12-14. The patients were informed about the Borg scale from the endurance-stress test. Every training session started with a co-ordination and stretching component, which lasted 10-15 min. The endurance training increased from $3 \times 10 \mathrm{~min}$, to $4 \times 10 \mathrm{~min}$, to $2 \times 20 \mathrm{~min}$, to $3 \times 20 \mathrm{~min}$, to $2 \times 30 \mathrm{~min}$, to $1 \times 40 \mathrm{~min}$, to $1 \times 50 \mathrm{~min}$, and finally, to $1 \times 60 \mathrm{~min}$, followed by a 5-10 min cooling-down period.

\section{Results}

The study commenced with 35 patients. After 12 weeks of intervention study, retention was $27 / 35$ (77\%) patients, and at 24 weeks, 24/35 (69\%) patients remained. Therefore, the data for 24 patients were fully evaluable. After 24 weeks, the HbAlc score was significantly reduced after intervention $(\mathrm{P}=0.001)$, whereas insulin and glucose levels remained unchanged.

After 6 months, the patients with involvement in the intervention demonstrated significant improvements in BMI $(\mathrm{P}=0.001)$ and endurance $(\mathrm{P}=0.013)$. When comparing fatigue scores, significant improvements were seen during intervention $(\mathrm{P}=0.008)$. Furthermore, the quality of life $(\mathrm{P}=0.007)$ was significantly improved. In addition, the patients involved in the intervention improved, following a specific trend in terms of their subjectively perceived exertion during the endurance-stress test $(\mathrm{P}=0.079)$. Changes in the IPAQ are shown in Table II. A general non-significant improvement was observed in the domain active transportation, as well as in the domains of domestic and garden activity and leisure time from T1 to T2 (Table II). The total activity score increased non-significantly from $\mathrm{T} 1$ to $\mathrm{T} 3$, with a minor decrease from
T2 to T3. A percentage increase in vigorous activity, and a simultaneous reduction of low and moderate activity from $\mathrm{T} 1$ to T3, were also detected (Table III).

Changes in endurance during the whole training process (W/kg per kg body weight), well-being during the endurance-stress test (as measured according to the Borg scale), fatigue, quality of life and glucose metabolism are presented in Table I.

\section{Discussion}

There exists limited data on the compliance and sustainability of the physical activity that is recommended following a breast cancer diagnosis. The present study describes compliance and sustainability of physical activity over a long time period in 24 patients with breast cancer. The results have confirmed that supervised physical activity is an excellent tool to improve physical activity compliance. In comparison, the HEAL study assessed physical activity levels among 806 breast cancer survivors (https://healthcaredelivery. cancer.gov/heal/). There was a marked trend of decreasing time spent in moderate-intensity, vigorous-intensity and sports/recreational activity with the increasing categories of BMI and age. Three years following a breast cancer diagnosis, only $32 \%$ of the breast cancer survivors were involved in the recommended levels of moderate-to-vigorous activity in terms of their recreational physical activity (6) Littman et al (7) examined the levels of physical activity in 315 primary breast cancer survivors, and observed how those levels changed following cancer diagnosis and treatment. After 12 months of diagnosis, the physical activity level decreased by $50 \%$ relative to the time prior to the diagnosis. An increase in the physical activity level was detected after 19-30 months following diagnosis, which was 3 MET/h/week lower compared with the situation prior to the diagnosis (7). Blanchard et al (8) reported on changes 
Table II. Changes determined in the IPAQ.

$\mathrm{T} 1$

$\mathrm{T} 2$

T3

P-value

(T1 vs. T3)

Work domain
Active transportation domain
Domestic and garden domain
Leisure-time domain
Total activity score

$493.56 \pm 1696.99$
$978.35 \pm 742.28$
$2,112.93 \pm 1854.66$
$909.96 \pm 1149.64$
$2,227.07 \pm 693.414$

$329.79 \pm 1648,99$
$1,138.93 \pm 1086.53$
$2,235.00 \pm 1931.65$
$2,313.30 \pm 3453.79$
$2,987.88 \pm 922.09$
$329.79 \pm 1648.99$
$917.25 \pm 925.38$
$2,170.84 \pm 1870.20$
$1,895.06 \pm 1261.13$
$2,666.22 \pm 830.56$

0.978

0.974

0.995

0.300

0.931

METs accomplished (over 7 days) at T1 (baseline), T2 (after 12 weeks) and T3 (after 6 months/24 weeks) following the initiation of intervention. The P-values were calculated using ANOVA, and data are expressed as the mean \pm standard deviation. MET, metabolic equivalent of task; ANOVA, analysis of variance.

Table III. PA levels of the patients (categorized as low, moderate or vigorous), determined at T1, T2 and T3.

\begin{tabular}{|c|c|c|c|c|c|c|c|c|c|}
\hline \multirow[b]{2}{*}{ PA level (\%) } & \multicolumn{3}{|c|}{$\mathrm{T} 1$} & \multicolumn{3}{|c|}{$\mathrm{T} 2$} & \multicolumn{3}{|c|}{ T3 } \\
\hline & Low & Moderate & Vigorous & Low & Moderate & Vigorous & Low & Moderate & Vigorous \\
\hline Work domain & 87.5 & - & 12.5 & 91.66 & - & 8.33 & 91.66 & - & 8.33 \\
\hline Transport & 8.33 & 70.83 & 20.83 & - & 75 & 25 & - & 83.33 & 16.66 \\
\hline Domestic and gardening & - & 45.83 & 54.16 & - & 41.66 & 58.33 & - & 41.66 & 58.33 \\
\hline Leisure time & 25 & 41.66 & 33.33 & 8.33 & 45.83 & 45.83 & 12.5 & 29.16 & 58.33 \\
\hline
\end{tabular}

Data for the PA levels are shown as percentages. PA, physical activity; T1, baseline; T2, after 12 weeks; T3, 6 months/24 weeks after the initiation of intervention.

in lifestyle following cancer diagnoses and reduced physical activity in $30 \%$ of their cancer patients (8).

In contrast with these observations, our supervised walking intervention led to an increase in the active transportation, domestic, garden and leisure time domains from T1 to T2. The minor drop from $\mathrm{T} 2$ to $\mathrm{T} 3$ could be accounted for by the winter season, which occurred at T3. Overall, an increasing trend of the total activity score was observed ( $\mathrm{P}$ for T1 vs. T2=0.796; $\mathrm{P}$ for $\mathrm{T} 1 \mathrm{vs.} \mathrm{T} 3=0.936)$. The total activity score correlates with the overall survival (OS), disease-free survival (DFS) and the time to progression (32). The Long-Island Breast Cancer Study examined the effect of post-diagnosis activity on survival in a cohort of 1,423 women with breast cancer between 1996 and 1997 (33). Survival rates were improved among women who were highly active following diagnosis (>9.0 MET/h/week) compared with inactive women ( $0 \mathrm{MET} / \mathrm{h} /$ week) for all-cause HR (0.33) and breast-cancer-specific mortality HR (0.27) (33). Similar results were reported by Courneya et al (32) with the Supervised Trial of Aerobic versus Resistance Training (START) trial.DFS was $82.7 \%$ for the exercise group compared with $75.6 \%$ for the control group at an 8 year follow-up (32).

Several randomized controlled trials (RCTs) have investigated the impact of physical activity on glucose metabolism in patients with metabolic syndrome. There is evidence to suggest that physical activity is effective in decreasing metabolic syndrome. Muscle contraction has a marked effect on glucose metabolism, when a physical stress $>20 \%$ of the maximum $\mathrm{O}_{2}$ absorption is applied $(13,14,16,22-24)$. The impact of physical activity on metabolism in breast cancer survivors has yet to be elucidated. This 6-month endurance intervention study, with a moderate-to-vigorous walking training program for 60-75 min twice-weekly among breast cancer survivors, led to decreased levels of HbA1c in this cohort. However, no effects on fasting insulin and glucose levels were identified.

Our results are in line with previously published observations. Schmitz et al (17) reported a significant increase in lean muscle mass, and a decrease in body fat, after 12 months of physical intervention. No effects were observed with respect to body weight, BMI, body fat and insulin (24). In a study by Fairey et al (16), a 15 week aerobic exercise program in postmenopausal breast cancer survivors did not result in any changes in the levels of fasting glucose, insulin or insulin resistance, although significant decreases in insulin-like growth factor 1 (IGF-1) and other IGF-binding proteins were identified (16). In an RCT with 65 postmenopausal breast cancer survivors, Thomas et al (20) identified a significant effect of moderate-intensity aerobic exercise [150 min (five sessions of $30 \mathrm{~min}$ ) per week over 6 months] on metabolic parameters from the baseline to 6 months. In contrast with our observations, Thomas et al (20) did describe changes in fasting blood glucose.

In RCTs, Friedenreich et al (22), Irwin et al (23) and Ligibel et al (24) described positive effects of physical activity on insulin and glucose levels [insulin resistance per Homeostasis Model Assessment (HOMA) index], the waist circumference, IGF-1 and IGFBP-3 concentrations and on the level of leptin $(17,23,24)$. The reason for this discrepancy 
compared with our data might be explained by the different doses of drugs administered, intensity of physical activity and anthropometric data of the patients. The range of the training sessions in our study was in line with the recommendations of the American College of Sports Medicine for breast cancer survivors, and the recommendations for age-appropriate guidelines from the Physical Activity Guidelines for Americans. According to these guidelines, adults aged 18-64 years should engage in at least $150 \mathrm{~min}$ per week of moderate intensity or 75 min per week of vigorous-intensity aerobic physical activity, or an equivalent combination of moderate and vigorous intensity aerobic physical activity (34).

In a review, Ghose et al (19) described the risk of obesity and insulin resistance on disease recurrence in patients with breast cancer. They concluded that a large-scale RCT to investigate the impact of physical activity on insulin resistance, weight, DFS and OS would be required for patients with breast cancer during, or just after, completion of the chemotherapy (19). To date, the impact of physical activity on metabolic syndrome in breast carcinogenesis has been poorly studied.

The changes in endurance, subjectively perceived exertion during an endurance-stress test, quality of life and fatigue identified in our study corroborate the results identified in another study (35).

However, there are certain limitations with the present study. Our data are limited by the small sample size and no control group. Therefore, it is our intention to verify the results in a follow-up study with a control group and an increased sample size.

Important for the sustainability of physical activity in the aftercare of patients with breast cancer are specifically offered incentives, such as assisted sport groups for patients with breast cancer. Our recommendation is that patients with breast cancer are informed about the feasibility of physical activity in aftercare directly at the initiation of therapy.

In conclusion, this study has demonstrated a great compliance with, and the sustainability of, the recommendations. The walking exercise program led to significant improvements in endurance, in the subjectively perceived exertion during an endurance stress test, in fatigue, quality of life and the levels of HbA1c. The aim of further research should be to implement a physical intervention program for an improved understanding of the effects of physical activity on glucose metabolism in breast cancer survivors.

\section{Acknowledgements}

We acknowledge the kind support of the Cancer Society Schleswig-Holstein.

\section{References}

1. Nichols HB, Trentham-Dietz A, Egan KM, Titus-Ernstoff L, Holmes MD, Bersch AJ, Holick CN, Hampton JM, Stampfer MJ, Willett WC and Newcomb P: Body mass index before and after breast cancer diagnosis: Associations with all-cause, breast cancer, and cardiovascular disease mortality. Cancer Epidemiol Biomarkers Prev 18: 1403-1409, 2009.

2. Vagenas D, DiSipio T, Battistutta D, Demark-Wahnefried W, Rye S, Bashford J, Pyke C, Saunders C and Hayes SC: Weight and weight change following breast cancer: Evidence from a prospective, population-based, breast cancer cohort study. BMC Cancer 15: 28, 2015
3. Sestak I, Cuzick J, Sapunar F, Eastell R, Forbes JF, Bianco AR and Buzdar AU; ATAC Trialists' Group: Risk factors for joint symptoms in patients enrolled in the ATAC trial: A retrospective, exploratory analysis. Lancet Oncol 9: 866-872, 2008.

4. Crew KD, Greenlee H, Capodice J, Raptis G, Brafman L, Fuentes D, Sierra A and Hershman DL: Prevalence of joint symptoms in postmenopausal women taking aromatase inhibitors for early-stage breast cancer. J Clin Oncol 25: 3877-3883, 2007.

5. Reinertsen KV, Cvancarova M, Loge JH, Edvardsen H, Wist E and Fosså SD: Predictors and course of chronic fatigue in long-term breast cancer survivors. J Cancer Surviv 4: 405-414, 2010.

6. Irwin ML, Smith AW, McTiernan A, Ballard-Barbash R, Cronin K, Gilliland FD, Baumgartner RN, Baumgartner KB and Bernstein L: Influence of pre- and postdiagnosis physical activity on mortality in breast cancer survivors: The health, eating, activity, and lifestyle study. J Clin Oncol 26: 3958-3964, 2008.

7. Littman AJ, Tang MT and Rossing MA: Longitudinal study of recreational physical activity in breast cancer survivors. J Cancer Surviv 4: 119-127, 2010

8. Blanchard CM, Denniston MM, Baker F, Ainsworth SR, Courneya KS, Hann DM, Gesme DH, Reding D, Flynn T and Kennedy JS: Do adults change their lifestyle behaviors after a cancer diagnosis? Am J Health Behav 27: 246-256, 2003.

9. Irwin ML, McTiernan A, Bernstein L, Gilliland FD, Baumgartner R, Baumgartner K and Ballard-Barbash R: Physical activity levels among breast cancer survivors. Med Sci Sports Exerc 36: 1484-1491, 2004.

10. Irwin ML, McTiernan A, Baumgartner RN, Baumgartner KB, Bernstein L, Gilliland FD and Ballard-Barbash R: Changes in body fat and weight after a breast cancer diagnosis: Influence of demographic, prognostic, and lifestyle factors. J Clin Oncol 23: 774-782, 2005.

11. Ibrahim EM and Al-Homaidh A: Physical activity and survival after breast cancer diagnosis: Meta-analysis of published studies. Med Oncol 28: 753-765, 2011.

12. Lahart IM, Metsios GS, Nevill AM and Carmichael AR: Physical activity, risk of death and recurrence in breast cancer survivors: A systematic review and meta-analysis of epidemiological studies. Acta Oncol 54: 635-654, 2015.

13. Xue F and Michels KB: Diabetes, metabolic syndrome, and breast cancer: A review of the current evidence. Am J Clin Nutr 86: s823-s835, 2007.

14. Dieli-Conwright CM, Mortimer JE, Schroeder ET, Courneya K, Demark-Wahenfried W, Buchanan TA, Tripathy D and Bernstein L: Effects of a 16-week resistance and aerobic exercise intervention on metabolic syndrome in overweight/obese latina breast cancer survivors cancer. Epidemiol Biomarkers Prev 24: 763, 2015.

15. Azrad M and Demark-Wahnefried W: The association between adiposity and breast cancer recurrence and survival: A review of the recent literature. Curr Nutr Rep 3: 9-15, 2014.

16. Fairey AS, Courneya KS, Field CJ, Bell GJ, Jones LW and Mackey JR: Effects of exercise training on fasting insulin, insulin resistance, insulin-like growth factors, and insulin-like growth factor binding proteins in postmenopausal breast cancer survivors: A randomized controlled trial. Cancer Epidemiol Biomarkers Prev 12: 721-727, 2003.

17. Schmitz KH, Ahmed RL, Hannan PJ and Yee D: Safety and efficacy of weight training in recent breast cancer survivors to alter body composition, insulin, and insulin-like growth factor axis proteins. Cancer Epidemiol Biomarkers Prev 14: 1672-1680, 2005.

18. Bouillet T, Bigard X, Brami C, Chouahnia K, Copel L, Dauchy S, Delcambre C, Descotes JM, Joly F, Lepeu G, et al: Role of physical activity and sport in oncology: Scientific commission of the national federation sport and cancer CAMI. Crit Rev Oncol Hematol 94: 74-86, 2015.

19. Ghose A, Kundu R, Toumeh A, Hornbeck C and Mohamed I: A review of obesity, insulin resistance, and the role of exercise in breast cancer patients. Nutr Cancer 67: 197-202, 2015.

20. Thomas GA, Alvarez-Reeves M, Lu L, Yu H and Irwin ML: Effect of exercise on metabolic syndrome variables in breast cancer survivors. Int J Endocrinol 2013: 168797, 2013.

21. Goodwin PJ, Ennis M, Pritchard KI, Trudeau ME, Koo J, Madarnas Y, Hartwick W, Hoffman B and Hood N: Fasting insulin and outcome in early-stage breast cancer: Results of a prospective cohort study. J Clin Oncol 20: 42-51, 2002. 
22. Friedenreich CM, Neilson HK, Woolcott CG, McTiernan A, Wang Q, Ballard-Barbash R, Jones CA, Stanczyk FZ, Brant RF, Yasui Y, et al: Changes in insulin resistance indicators, IGFs, and adipokines in a year-long trial of aerobic exercise in postmenopausal women. Endocr Relat Cancer 18: 357-369, 2011.

23. Irwin ML, Varma K, Alvarez-Reeves M, Cadmus L, Wiley A, Chung GG, Dipietro L, Mayne ST and Yu H: Randomized controlled trial of aerobic exercise on insulin and insulin-like growth factors in breast cancer survivors: The yale exercise and survivorship study cancer. Cancer Epidemiol Biomarkers Prev 18: 306-313, 2009.

24. Ligibel JA, Campbell N, Partridge A, Chen WY, Salinardi T, Chen H, Adloff K, Keshaviah A and Winer EP: Impact of a mixed strength and endurance exercise intervention on insulin levels in breast cancer survivors. J Clin Oncol 26: 907-912, 2008.

25. Borg G: Borg's perceived exertion and pain scales. Champaign, IL: Human Kinetics; viii, 104p, 1998.

26. Wahlund H: Determination of the physical working capacity. Acta Med Scand 215 (Suppl): S83-S98, 1948.

27. Craig CL, Marshall AL, Sjöström M, Bauman AE, Booth ML, Ainsworth BE, Pratt M, Ekelund U, Yngve A, Sallis JF and Oja P: International physical activity questionnaire: 12-country reliability and validity. Med Sci Sports Exerc 35: 1381-1395, 2003.

28. Høyer M, Johansson B, Nordin K, Bergvist L, Ahlgren J, Lidin-Lindqvist A, Lambe $M$ and Lampic C: Health-related quality of life among women with breast cancer-a population-based study. Acta Oncol 50: 1015-1026, 2011.
29. Eyigor S, Karapolat H, Yesil H, Uslu R and Durmaz B: Effects of pilates exercises on functional capacity, flexibility, fatigue, depression and quality of life in female breast cancer patients: A randomized controlled study. Eur J Phys Rehabil Med 46: 481-487, 2010.

30. Schwarz R, Krauss O and Hinz A: Fatigue in the general population. Onkologie 26: 140-144, 2003.

31. Smets EM, Garssen B, Bonke B and De Haes JC: The multidimensional fatigue inventory (MFI) psychometric qualities of an instrument to assess fatigue. J Psychosom Res 39: 315-325, 1995.

32. Courneya KS, Segal RJ, McKenzie DC, Dong H, Gelmon K, Friedenreich CM, Yasui Y, Reid RD, Crawford JJ and Mackey JR: Effects of exercise during adjuvant chemotherapy on breast cancer outcomes. Med Sci Sports Exerc 46: 1744-1751, 2014.

33. Bradshaw PT, Ibrahim JG, Khankari N, Cleveland RJ Abrahamson PE, Stevens J, Satia JA, Teitelbaum SL, Neugut AI and Gammon MD: Post-diagnosis physical activity and survival after breast cancer diagnosis: The long island breast cancer study. Breast Cancer Res Treat 145: 735-742, 2014.

34. US Department of health and human services. Physical activity guidelines for Americans. Washington, DC: US Department of health and human services; 2008.

35. Schmitz KH, Courneya KS, Matthews C, Demark-Wahnefried W, Galvão DA, Pinto BM, Irwin ML, Wolin KY, Segal RJ, Lucia A, et al: American college of sports medicine roundtable on exercise guidelines for cancer survivors. Med Sci Sports Exerc 42: 1409-1426, 2010. 